RESUMO: A história da arte latinoamericana na Alemanha no século XX muilo deve aos emigrantes e exilados. Erwin W. Palm, único historiador da arle a retornar, foi professor em Heidelberg. $e$ grande conhecedor da arle colonial iberoamericana. Mas depois dele (orientou teses nos anos 70) a disciplina não conseguiu enraizar-se nas universidades da Alemanha; lá há poucus perspectivas de pesquisa academica. Museus com diretores dinàmicos e aberlos começam a perceber a importancia de artistas latino-americanos. Há interesse entre os estudantes, e em algumas galerias de arte. $E$ há projetos alemães no México e em outros paises, relacionados à arqueologia e à conservação de patrimonio. A necessidade de recuperar o tempo perdido é enorme. Sugere-se que a Universidade de Heidelberg reative esta disciplina conservando seu acervo bibliográfico $e$ de diapositivos. A contribuição da história da arte $\dot{e}$ indispensável para uma compreensão dos contextos internacionais e para a derrubada de representações de tipo cliche que continuam transmitidas pela ótica eurocėntrica.

PALAVRAS-CHAVE: Arte latino-americana. México. Artistas emigrantes alemàes. Heidelberg. Berlim. Universidades alemãs. Professor Erwin Palm. Pesquisa em projetos internacionais.
HANS HAUFE

\section{História da} arte latinoamericana na Alemanha

$A$

ntes que en la vida politica, esta capacidad de recreación creadora se ha manifestado poderosamente en nuestra vida artística.

Carlos Fuentes Tiempo mexicano
Porto Arte, Porto Alegre, v. 5, n. 8, p. 65-80, nov. 1993 


\section{INÍCIOS E PRÉ-HISTÓRIA}

A América inspirou desde sempre a fantasia de artistas europeus (KOHL, 1982). Já o próprio Dürer deixou-se fascinar pelos tesouros astecas que viu em Bruxelas; contatos mais intensos, porém, só se tornaram possiveis após o término do dominio colonial espanhol.

Um estudo comparativo da política cultural européia e latino-americana do século XIX deixa reconhecer uma diferente situaçâo de interesses. Como o exemplo do México o mostra, as motivações eram opostas, como bem se pode imaginar: enquanto o jovem Estado se abria, cheio de simpatia pela Europa, e tentava encontrar conectar-se com o desenvolvimento cultural internacional, os novos interlocutores fixavam-se sobretudo no aspecto econômico. As atividades diplomáticas do México visavam ao reconhecimento e ao intercâmbio, o pais queria incorporar-se ao circulo das nações como parceiro com iguais direitos. Já em 1824 organizava em Londres uma exposição de arte précolombiana; atividades européias deste tipo no México não são conhecidas, se abstraímos do interesse de alguns diplomatas pela arte mexicana. No transcurso do século XIX reforçaram-se as disparidades, a exportação cultural européia tornou-se dominante.

Artistas europeus foram engajados na reorganização da tradicional Academia de San Carlos, fundada já em 1785 , no quadro de referência das reformas borbônicas. Os italianos Claudio Linati, Pietro Gualdi e Eugenio Landesio e os catalães Pelegrín Clavé e Manuel Vilar ocuparam por longos prazos posições de liderança e, num processo de aproximação à realidade desconhecida, identificaram-se tão fortemente com o país que os hospedava, que até foram esquecidos $\mathrm{em}$ suas pátrias. Até hoje a história da arte estudada na Europa ainda não descobriu estes artistas como os precursores de uma primeira cooperação intercultural. Seus trabalhos encontraram tão pouco acesso aos museus europeus como as obras daqueles artistas que trabalharam no Novo Mundo seguindo as pegadas de Alexander von Humboldt. Seus painéis transmitem uma visão multifacetada da cultura latino-americana do século XIX. No centro destas obras aparecem ruínas précolombianas, vistas de cidades, construções coloniais e cenas populares, bem como temas etnográficos. Os livros ilustrados encontraram na América Latina um público entusiasmado. Especialmente fecunda para a pesquisa foi a cooperação dos artistas com os arqueólogos, empenhados no levantamento de uma documentação científica. De Carl Nebel (1805-55), de Hamburgo, provêm os primeiros registros exatos (em litografias) das ruinas de Xochicalco, La Quemada e El Tajin no México, enquanto o inglês Frederick Catherwood trabalhava com o arqueólogo John Lloyd Stephens no terreno das culturas maias. Só bem mais 
tarde a pesquisa alemã haveria de voltarse para uma renovação destas relações culturais (LÖSCHNER, 1978).

Em contraste com o ardente interesse dos artistas, os historiadores da arte alemães descuraram completamente a América Latina até 1960. Tampouco se deixaram inspirar pelo estudo da América pré-colombiana [Altamerikanistik], que já se constituira em 1875 no Congresso dos Americanistas. As razões desta atitude de isolação [Abschottung] precisariam ser analisadas numa detalhada definição da posição [Standorl bestimmung]. Desde os anos 20 aprofundaram-se sobretudo os conhecimentos europeus das culturas pré-colombianas; para Henry Moore, foi uma experiência-chave o seu encontro com a arte do México antigo.

Despertar compreensão para culturas estrangeiras era até recentemente um domínio da etnologia. A história da arte só recebeu estímulos graças à geração dos emigrantes. A guerra e o apósguerra tinham conduzido uma série de historiadores da arte alemães à América Latina, sobretudo ao México, conforme a tradição. A atividade deles se tornou exemplar: Mathias Goeritz, após seu doutoramento em Berlim (1940) sobre a pintura de retratos saxônicos, salvou-se passando pela Espanha e chegando ao México, onde cunhou gerações de artistas, como professor universitário em Guadalajara e na Cidade do México. Só depois de ter surgido a respeito dele uma dissertação de doutorado de Heidelberg (WERRY, 1991), a Academia de Arte de Berlim, da qual Goeritz foi membro, prepara uma exposição comemorativa. Também Paulo Westheim foi confrontado, por sua fuga, com uma cultura que
The era completamente estranha. Seus estudos sobre a arte pré-colombiana tornaram-se clássicos, no México. Paralelamente surgiu uma série de publicaçõcs igualmente quase ignoradas na Alemanha - que apontavam caminhos sobre o modernismo mexicano. Heinrich Berlin, desde sua juventude no México, tornouse um dos mais profundos conhecedores da arte colonial (1979). O historiador da arquitetura Horst Hartung trabalha na Universidade de Guadalajara. O Brasil se tornou para Wolfgang Pfeiffer, depois de uin doutoramento sobre o barroco, $o$ novo lar, para sempre. Ele dirigiu o Museu da Universidade de São Paulo, com uma famosa coleção do modernismo clássico e foi um professor universitário de renome. Em geral é preciso dizer que nenhuma universidade alemã interessou-se pelas experiências destes emigrantes, um paralelo assustador com o século XIX.

Na América Latina, ao contrário, os emigrantes alemães experimentaram uma valorização extraordinária. Sua atividade, contudo, não pode ser considerada propriamente como um mérito da história da arte alemã, pois resultou, isto sim, da pressão exterior. Isto fica especialmente nítido na vida e na obra de Erwin Walter Palm, o único historiador da arte a retornar após um exílio de mais de 20 anos.

Palm veio em 1940 para a $\mathrm{Re}$ pública Dominicana, passando por Londres. Tornou-se professor de arqueologia e história da arte e iniciou a conservação dos monumentos daquele pais caribenho. Pontos centrais de suas pesquisas situavam-se na época colonial, em questões da aculturação, na iconografia e na história da arquitetura, no 
urbanismo histórico, mas também na arte pré-colombiana e no modernismo. Ao lado disso, a literatura sempre o fascinou. Graças à sua amizade com Manuel Toussaint e Francisco de la Maza, os fundadores da história da arte mexicana e do Instituto de Investigaciones Estéticas da Universidade Nacional da Cidade do México, surgiram desde 1951 vínculos estreitos com este país. A fama internacional de Palm baseou-se em sua obra principal sobre os monumentos arquitetônicos de Santo Domingos (1955), que estabeleceu parâmetros para a pesquisa latinoamericana. (Mais, a este respeito, em: PALM, 1974).

2. A INTRODUÇÃO DA HISTÓRIA DA ARTE LATINO-AMERICANA COMO DISCIPLINA UNIVERSITÁRIA

Em 1960, Palm recebeu uma nomeação para a Universidade de Heidelberg, para colaborar na concepção de uma história da arte orientada em termos globais. Com isso, a paisagem universitária alemã foi enriquecida com uma nova disciplina especializada. Isso aconteceu, porém, sob a forma de um implante. Desde o início, os parcos recursos, o acervo modesto, como se pode imaginar, e o estado das bibliotecas locais tiveram uma influência inibidora. Os interesses interdisciplinares de Palm conduziram a uma estreita cooperação com as disciplinas vizinhas. Graças à sua participação em congressos internacionais, ele inspirou a pesquisa sobre a América Latina em sua totalidade e colaborou muito para a boa fama de Heidelberg. Desde 1964 suas experiências influenciaram o projeto PueblaTlaxcala da DFG [Deutsche Forschungsgemeinschaft], coordenado também por ele, durante algum tempo.

Não se chegou, porém, a uma ampliação e um reforço [Ausbau] da disciplina especializada. Tudo ficou restrito à pessoa de Palm. Muitas vezes falou-se, erroneamente, de um Departamento Ibérico. Este, porém, não chegou a ser fundado, no sentido jurídicouniversitário, porque Palm, em termos temáticos sempre interessado fortemente pela Espanha, esforçou-se por uma integração na história da arte européia, por ele interpretada como universal. No empreendimento científico tradicional da Alemanha, também a Espanha até hoje é na medida do possivel marginalizada.

\section{A PESQUISA EM HISTÓRIA} DA ARTE DESDE 1970

\subsection{Heidelberg}

Enquanto a pesquisa alemã sobre a América Latina pode assinalar desde os anos 70 um considerável desenvolvimento em muitas disciplinas, ela ficou presa, no dominio universitário, na área da história da arte, meramente às atividades de Palm. Este havia reconhecido claramente as dificuldades agravantes para uma aceitação do novo dominio científico também na área de história. Paradoxalmente, os interesses de Palm foram encarados como especialização exótica, apesar de sua enormemente ampla ramificação [Ausfücherung] (PALM, 1983). A partir dos pressupos- 
tos dados, não foi possivel estabelecer a história da arte da América Latina como uma disciplina parcial no domínio acadêmico. Em parte alguma organizouse uma outra cátedra universitária definida nestes termos, nem ao menos na forma de posto de professor assistente.

Sob a orientação de Palm surgiram, além dos artigos sobre pesquisas internacionais $\mathrm{cm}$ que ele participava, cinco dissertações de doutoramento em Heidelberg:

Arenas (1970), Luks (1972), Haufe (1977 [1978]), Tejeira-Davis (1987) e Cuadra (1987 [1991]), tendo este último concluído seu trabalho em Darmstadt. Estímulos das disciplinas aparentadas podem ser percebidos nitidamente em Luks, Tejeira-Davis e Cuadra, que também são arquitetos diplomados, e mais tarde também na atć agora única tese de habilitação com um tema latinoamericano surgida nos países de língua alemã (HAUFE, 1990).

Após a aposentadoria de Palm, a reocupação de sua cátedra mostrou-se complicada. Ela foi remanejada para reforçar o novo Departamento de História da Arte Européia. Mesmo quando já se podia perceber que a orientação "paralela" daquela área de concentração, mencionada nos editais do concurso, não era oferecida, nem então o Instituto de História da Arte desenvolveu qualquer nova concepção. A erosão começou. Não obstante, diversos trabalhos puderam ser levados adiante por um professor assistentc: entre 1981 e 1987 a Biblioteca Ibérica, cujo valor está em sua vinculação com a Espanha, Portugal, América Latina e a arte pré-colombiana, foi ampliada, transferida para o sistema RAK e seu arquivo de diapositivos foi aumentado. A par disso, novos contatos internacionais foram travados. Em 1987 ocorreu o remanejamento do cargo de professor $\mathrm{Cl}$ e do orçamento da biblioteca. Desde então, nenhum eco encontraram as sugestões de, através de professores visitantes, pesquisas com meios de terceiros e contratações temporárias [Lehraufträge] etc., pelo menos assegurar os elementos materiais para uma futura revitalização. Que esta tradição de pesquisa tenha sido abandonada, é tanto mais de se lamentar por ocorrer esta liquidação gradual em uma época de crescente interesse internacional pela Espanha e pela América Latina. Em Heidelberg existem elementos materiais para os quais não há nenhum substituto em todo o universo de língua alemã. $A$ preservação daquilo que ficou organizado é tão importante, além disso, porque a história da arte latino-americana foi fortemente descurada nas bibliotecas centrais alemãs em seu conjunto.

\subsection{Sobre a situação em outras universidades \\ Quem, apesar de todas as dificul- dades, decidiu-se por um tema latino-


americano, correu um grande risco: era preciso conquistar para orientadores professores a quem muitas vezes a matéria era desconhecida. $\Lambda$ situação de fontes escassas pressupõe esforços desproporcionalmente maiores do que no caso de temas comparáveis da história da arte européia, para os quais já existem trabalhos prévios. $O$ fato de que apesar das perspectivas profissionais muito inseguras tenha surgido em outras cidades uma série de dissertações de doutoramento, deve ser atribuido ao fascinio da América Latina. Mencionem-se os trabalhos de Berlim de Prignitz (1981), Gretenkord (1984) e Hulek-Gnärig (1988), dissertações de Kaiserslautern (DREWES, 1984), Aachen (BÜHLER, 1990) e Rostock (HAUPT, 1979). Em fase de conclusão está o projeto $O$ Ancestralismo - busca de identidade cultural na pintura abstrata da América Latina, de Rith-Magni (MÜNSTER).

Enquanto dois doutorandos de Palm, os latino-americanos Luks e Tejeira-Davis, conseguiram estabelecerse em universidades de seus países de origem, a situação profissional dos outros é precária. Com exceção da Sra. Hulek-Gnärig, que atua na Casa das Culturas do Mundo, em Berlim, resta aos que terminaram seu doutorado apenas a colaboração $\mathrm{em}$ projetos de exposições c de publicações, a reorientação (de estudos) - ou a emigração (DREWES, KETTENMANN). Campos profissionais duradouros relacionados com a América Latina são tão pouco visiveis quanto o fomento decisivo de uma área de concentração mediante a nomeação de um professor catedrático [Ordinarius] de história da arte. Traba-
Ihos de mestrado altamente qualificados não encontram continuação, dissertações de doutorado são interrompidas. Assim se esbanja um valioso potencial.

Detlef Noack desenvolveu, como professor da Escola Superior das Artes de Berlim, interesses latino-americanos, mas só depois de sua aposentadoria pode segui-los com força total. Seu projeto de pesquisa empenha-se por uma documentação detalhada das construções sacras ibero-americanas do periodo colonial, tendo como ponto principal igrejas de aldeias, paróquias e abadias fora dos grandes centros. Aqui seria possivel integrar historiadores e historiadoras da arte mais jovens que tenham interesses de conservação de monumentos históri$\cos \mathrm{e}$ artísticos.

\subsection{Pesquisas fora das univer- sidades}

Devido à ausência de espaço institucional para uma pesquisa profissional de história da arte latino-americana fica sempre mais dificil não perder a conexão, no contexto internacional, enquanto pessoa individual. Diferentemente de outras disciplinas, que apesar de dificuldades conseguiram impor nos anos 70 uma orientação para a América Latina dentro do quadro de referência da disciplina-matriz, a tradicional orientação centripeta desta disciplina de massas que é a história da arte é tão forte que a América Latina vem a ser encarada como lator perturbador, porque os problemas do subconsciente arrebentam os limites pré-delinidos.

Em alguns casos, a dedicação à América Latina ocorreu após uma sólida formação em outros campos e um dou- 
toramento no domínio europeu, como ocorreu com Helga von Kügelgen, que trabalhou, nos quadros do Projeto México da DFG, sobre arte colonial e iconografia. No livro-homenagem [Festschrifi] que ela editou (PALM, 1983) foram publicados abundantes trabalhos originais de discipulos e amigos de Palm, que ao mesmo tempo esboçam as até agora quase não aproveitadas possibilidades de cooperação internacional. Von Kügelgen está trabaIhando atualmente no Projeto Portais de honra para os Habsburg - Arcos de Iriunfo para os Vice-Reis no Novo Mundo.

Uma exceção positiva é constituída pela atividade da Comissão de arqueologia geral e comparada, em Bonn, cuja área de concentração está, aliás, no domínio das pesquisas de campo arqueológicas das culturas préhispânicas da América Latina. Seu diretor cientifico, Wolfgang Wurster, trabaIha, a par de sua atividade funcional principal, sobre história da arquitetura e do urbanismo do periodo colonial.

\section{$3.4 \mathrm{O}$ papel dos museus}

A América Latina foi encarada, durante um longo tempo, apenas como um ramo do tronco histórico da cultura européia, e no melhor dos casos the foi imposto um papel de folclore. A arte do subcontinente nunca teve, até hoje, uma chance honesta de participar ativamente no processo de controle de normas, que definiu sob a pressão do mercado e sob a direção norte-americana/européia as pretensões culturais mundiais. Isso se demonstra, por exemplo, pela participação reduzida a contribuições ocasionais de artistas latino-americanos nas Documenta, ou pela completa marginalização [Ausgrenzung] da arte do subcontinente pelos grandes museus estatais, nenhum dos quais possui uma seção de arte latino-americana. Como se nos últimos quinhentos anos não tivesse ocorrido nenhum desenvolvimento cultural, encontram-se nas conhecidas coleções apenas esporadicamente alguns trabaIhos sobre Botero, Lam ou Matta, que ficaram conhecidos através de exposições em Paris.

Esta situação vergonhosa topa na América Latina com incompreensão e vem a ser interpretada como uma conseqüência tardia do colonialismo. Os métodos com os quais a exportação da cultura européia salvou sua pretensão exclusivista de eficiência, progresso e modernidade na atualidade afetam diretamente a responsabilidade da história da arte. Uma mudança neste estado de coisas, contudo, não se esboça através da contribuição da pesquisa universitária, mas provém antes de engajados diretores de museus, cujo interesse pela América Latina vem crescendo. Enquanto as publicações cientificas constituem notáveis raridades (DEMM, 1991), a maioria das dissertações de doutoramento sobre a América Latina ou não são publicadas ou somente em edições pequenas, e relatórios ou comunicações de pesquisa só atingem um reduzido público no exterior ou em atas de jornadas, os catálogos de exposições, elaborados conforme as mais altas exigências, podem contar com um eco bem mais amplo. Neles aparecem também textos de historiadores da arte latino-americanos em tradução alemã - da miséria fazse uma virtude, na medida em que assim 
o público alemão toma conhecimento de uma perspectiva de outro tipo. Como pioneiros atuaram a Galeria de Arte Municipal [Städtische Kunsthalle] de Düsseldorf sob a direção de Jürgen Harten com a exposição Pintura barroca dos Andes (1976) e instituições de Berlim, sobretudo a associação artística Nova sociedade de artes plásticas. Em Berlim, tornou-se um dos temas principais a história do descobrimento da América Latina, tanto quanto o muralismo mexicano e três de seus principais mestres, Orozco, Rivera e Tamayo, para o que forneceram as contribuições escritas especialmente Münzberg (1984) e Nungesser (1990), e ainda a fotografia da América Latina (BILLETER, 1981), o Associações de arte assumiram a corajosa tarefa de apresentar artistas latino-americanos ainda desconhecidos na Alemanha atualidade.
Associações de arte assumiram a corajosa tarefa de apresentar artistas latino-americanos ainda desconhecidos na Alemanha. Em 1978 a Galeria de Arte Schirn, de Frankfurt cstatuiu novos padrões com a exposição Imagen de Mexico, organizada por Erika billeter, uma apreciação abrangente do modernismo mexicano. As Semanas Festivas de Viena assumem esta representação, que atinge até a

Que a arte contemporânea da América Latina tenha conseguido um forum na Alemanha, é sobretudo mérito da Galeria Ruta Correa, que, atuando há doze anos em Freiburg, realizou trabalho de pioneiro. Além disso, foi fundada em 1991 a Casa de Cultura da América Latina, em Colônia, com a Galeria Cidade Branca (Weiße Stadt).

Quase não se pode estranhar que os meios de comunicação alemães não consigam acompanhar este desenvolvimento positivo. Mesmo exposições que só são encenadas uma vez ficam sem ser comentadas. Artigos a este respeito não aparecem nem ao menos uma vez por ano na Revista de Historia da Arte ou na ART-Magazin, de grande tiragem. A revista Humboldt, uma louvável exceção, só se consegue no exterior.

Ainda que no campo dos museus se esteja esboçando, com mais vigor a partir dos anos 80, uma abertura para temas latino-americanos, continua havendo ainda consideráveis lacunas. Paises inteiros permanceceram completamente desconhecidos. $\Lambda$ organização 
de uma mostra coletiva pública de arte da América Latina já está tão atrasada quanto a contribuição da pesquisa.

\section{DEFINIÇÃO DA POSIÇÃO}

São complexas as razões da marginalização sistematicamente promovida da América Latina no terreno universitario. Não basta recorrer ao provincianismo, às escolas superiores superlotadas, ao autocentrismo e às lutas nas distribuições, ainda que tais motivos decerto desempenhem um certo papel. A veemência da recusa faz pensar em um tabu, uma maldição, um profundo medo de contatos e preconceitos que só raramente vêm a ser formulados em observações atenuadoras, de que a gente quereria ocupar-se com "altas culturas". A situação, psicologicamente, é tão complicada quanto possível, dado que a arte mexe, como talvez nenhum outro domínio, com a própria autocompreensão.

A história da arte é, por própria natureza, uma história de relações. As culturas da América e da Europa achamse tão fortemente referidas uma à outra que se deveria esperar, a longo prazo, da pesquisa da América Latina, uma alteração fundamental de perspectivas. Isto é incômodo e é empurrado para uma geração posterior, que então poderia redescobrir as pesquisas de Palm como uma verdadeira revelação. A isso se acrescem motivos externos: a administração permanente da crise (tão acertadamente esboçada no artigo deste volume sobre $a$ ciência política), mal deixa espaço para o estabelecimento de uma especialização nova, voltada para o futuro, se as áreas de concentração dominantes na pesquisa já absorvem todas as energias. Com isso se fecha o círculo.

Erwin Panofsky, com sua famosa frase de que o observador das obras de arte históricas assemelha-se a um selvagem que na Santa Ceia de Leonardo da Vinci inicialmente só consegue reconhecer comensais bem vestidos discutindo vivamente, certamente não pensou num sentido dialético nas dificuldades que ocorrem na Alemanha para a recepção da arte latino-americana: aquilo que é historicamente estrangeiro permanece excluido principalmente porque faltam as categorias da experiência no trato com uma região cunhada de maneira diferente em termos culturais. Quem está acostumado a só ver paralelismos e correspondências não consegue fazer justiça com a América Latina. $O$ problema da comunicação com o método de uma aproximação em três etapas, de Panofsky, poderia ai servir de modelo de compreensão: após a apresentação descritiva do material, a análise do sujeito individual e depois uma reconstrução dos traços essenciais simbólicos em que se manifestam o conteúdo histórico, mas também a dimensão intemporal ou mesmo supratemporal da obra de arte poderiam abrir o acesso à realidade estranha. Isso inclui, evidentemente, uma familiaridade com o fundo histórico e social da Espanha e da $\Lambda$ mérica Latina, bem como um conhecimento das fontes e dos contextos e conexões. Uma vez que a pesquisa da história da arte sobre a Espanha está pouco desenvolvida na Alemanha e, na medida $\mathrm{cm}$ que ela se ocupa com temas clássicos medievais, praticamente não tem nenhum ponto de contato apropriado, não se pode esperar dela em tempo 
previsível nenhuma contribuição que apóic aquela.

Apesar de sua estreita vinculação com a história da arte européia da modernidade, nossa disciplina ficou desterrada.

\section{PERSPECTIVAS}

\subsection{Possibilidades}

Já que a pesquisa de história da arte a nivel internacional em seu conjunto desdenhou a América Latina, resultam para os pesquisadores alemães perspectivas notavelmente favoráveis. A contribuição espanhola geralmente se fixou sobre o período colonial e a arte pré-colombiana, uma restrição que do ponto de vista latino-americano aparece como absurda. Mais recentemente foram publicados importantes trabalhos sobre o urbanismo histórico, que pode contar com forte interesse nas jornadas hispano/latino-americanas, já que ele tem, no contexto dos esforços pela salvação da herança cultural, significação prioritária. Diante do acelerado processo de urbanização, a conservação de monumentos enfrenta tarefas quase insolúveis. Cooperação internacional, por exemplo nos quadros de referência da UNESCO ou acordos bilaterais tornamse sempre mais urgentes. Que neste campo a Alemanha se engaje pouco, é insustentável em termos de politica cultural. Exceções, como a iniciativa privada para a restauração de igrejas das Reduções Jesuíticas no Paraguai, a atividade de Dirk Bühler em Puebla e os projetos de conservação de monumentos na América Latina, perseguido por
Detlef Noack, comprovam enfaticamente o que seria possível.

Enquanto países como Argentina. Brasil e Colômbia dispõem de uma própria tradição de pesquisa, no caso do México já com 60 anos, a história da arte em outros países está presente apenas como um domínio parcial da história da arquitetura nos quadros de referência da formação dos arquitetos.

Para a contribuição da pesquisa alemã oferecem-se, portanto, no conjunto, atraentes atividades. A necessidade de recuperar o tempo perdido é enorme. $\mathrm{Na}$ longa lista dos desiderata assinalemse a pesquisa urbana, vastos dominios da arte colonial, os desenvolvimentos das correntes acadêmicas e costumbristas após a independência, a arquitetura da produção, das construções estatais, as artes gráficas, a modernidade clássica e tendências contemporâneas, mas também as relações mútuas com a Europa, temas iconográficos, possiveis questionamentos comparativos e interdisciplinares.

Por parte dos latino-americanos existe um encorajador interesse em uma cooperação com cientistas e instituições alemães. Ai se encontra uma chance única que poderia enriquecer o empreendimento cientifico alemão. Apesar de todas as criticas possiveis, também o Projeto México obteve uma série de efeitos positivos que deveriam ser avaliados. Isso vale especialmente para a história da arte.

\subsection{Sugestões}

A Universidade de Heidelberg deveria em todo caso preservar seus valiosos acervos - a Biblioteca Ibérica, o 
arquivo de diapositivos e as respectivas possibilidades de trabalho. Até a reconstrução de uma sólida estrutura, uma cadeira de professor visitante com recursos de fundações, contratos docentes complementares e pesquisas com meios de terceiros poderiam manter um funcionamento mínimo. A revitalização de uma cátedra remanejada é difícil. Mesmo assim, esta disciplina em Heidelberg não deveria ser construida a partir do nada. Graças às disciplinas próximas que ai são estudadas existem possibilidades que deveriam ser aproveitadas. Indiscutivelmente, a expansão da oferta docente seria um grande ganho, porém se este salto dará bom resultado, é completamente incerto e depende de uma concepção correspondente que 0 apóie. Isto está por enquanto na responsabilidade daqueles que tomam as decisões. $O$ interesse da nova geração é grande. Como Birle e Mols constatam para a ciência política, também as "tentativas" feitas até agora na História da arte latino-americana têm encontrado uma alegre e continua aceitação.

As experiências de Heidelberg têm mostrado que a existência de uma especialização de tipo novo não pode ser deixada por conta da constelação, que muda rapidamente, de um único Instituto. No interesse de futuras possibilidades de trabalho seria necessária uma série de medidas dirigidas, que porém teriam de ser iniciadas pelos representantes de disciplinas aparentadas.

Dentro do contexto deste meu relato foi consultada uma séric de representantes renomados da História da arte européia. Não foi possivel encontrar nenhuma cátedra interessada numa co- orientação, qualquer que fosse a estruturação desta. As consultas foram respondidas negativamente, com a indicação de excesso de encargos, ou amigavelmente contornadas ou nem mesmo respondidas. Por ocasião da ocupação de cátedras definidas de forma geral com área de concentração na época moderna européia, já fỉca, de regra, apartada a Espanha. Especialistas em América Latina provavelmente não teriam nenhuma chance.

Nesta situação é ineludivel que um Instituto para a América Latina, já estabelccido, ou uma correspondente área de concentração $\mathrm{em}$ uma universidade alemã ou alguns representantes isolados das disciplinas aparentadas assumam a iniciativa para instituir uma vaga respectiva em seu domínio próprio. Se isso não ocorrer em 1992, mais uma chance ficará inutilizada. Dado que se trata de uma iniciativa inovadora, os meios respectivos poderiam ser conseguidos adicionalmente. $O$ pedido deve ser fundamentado enfaticamente frente às organizações de fomento.

Também aqui podem-se imaginar diferentes possibilidades. Historiadores da arte qualificados com doutorado poderiam facilmente integrar-se em projetos interdisciplinares em uma séric de disciplinas: geografia, arqueologia, história, urbanística, etnologia, para nomear somente algumas. Todos os que foram consultados estavam interessados nisto. $\Lambda$ colaboração com historiadores da arte latino-americanos seria mais um enriquecimento suplementar na fase de estruturação. $\Lambda \mathrm{s}$ reviravoltas futuras colocarâo a pesquisa da América Latina diante de novas tarefas inimagináveis, para cuja realização se atribui cres- 
cente importância para as ciências da cultura.

Se no final deste século ainda se espera da história da arte uma contribuição relevante, a necessidade de ação é aguda. O tempo urge, dado que as novas gerações de cientistas de ambos os sexos desistem e emigram para outras profissões. A cientific community teria de discutir a forma adequada de "adoção". Na praxis tradicional da reprodução acadêmica há pouco espaço para começos inovadores, porém neste caso os interesses poderiam se completar. Resta esperar que este balanço iniciado pela ADLAF $^{1}$ apresente resultados positivos. Caso contrário, valeria para a história da arte o ditado: o próprio defunto carrega a vela.
Os vastos processos econômicos, políticos e ideológicos que transformam a América Latina têm também, não por último, uma dimensão cultural, da qual resulta para a história da arte a necessidade de uma colaboração que ultrapasse os limites das disciplinas. Apesar de toda a pressão para a restrição à própria área, está na hora de se explorar novos horizontes que pudessem superar o dilema da pesquisa alemã sobre a América Latina. Esta contribuição da história da arte é indispensável para uma compreensão dos contextos internacionais e para a derrubada de representações de tipo clichê que continuam transmitidas por uma ótica eurocêntrica que continua atuante. 


\section{NOTAS}

${ }^{1}$ ADLAF: Arbeitsgemeinschaft Deutsche Lateinamerika - Forschung (Grupo de trabalho de pesquisa alemã sobre a América Latina), que publica o manual de onde este artigo foi extraido.

\section{REFERÊNCIAS BIBLIOGRÁFICAS}

ANDERS, F.; KAUFFMANN DOIG, F. Peru durch die Jahrlausende. Recklinghausen: Kunst und Kultur im Lande der Inka, 1984.

BAQUE, E.; SPREITZ, H. (Hg.). Jose Clemente Orozco. Berlin, 1981.

BERLIN. H. Arquitectura y arquifectos coloniales de Oaxaca: la catedral. In: Archivo Español de Arte. Madrid: 52, 1979. p.307-328.

BILLETER, E. (Hg.) Fotografie Lateinamerikas von 1860 bis heute. Bern. (Hg.) Imágen de México. Der Beitrag Mexikos zur Kunst des 20. Jahrhunderts. Frankfurt.

BUHLER, D. Das Bürgerhaus der Kolonialzeit in Puebla. Saarbrücken, 1990.

CUADRA, M. Architektur in Lateinamerika. Die Andenstaaten Chile, Ecuador, Bolivien und Peru im 19. und 20. Jahrhundert. Darmstadt, 1991.

DEMM, E. Spanische Kolonialpalaste in Mexiko. Köln, 1991.

DREWES, M. W. Das Colegio de Cristo. ein mexikanisches Unterrichtsgebäude aus der Barockzeit und seine baugeschichtliche Entwicklung. Kaiserslautern, 1984.

GOERITZ, M. Gedanken zur Kunst der Gegenwart und Zukunft. Linz, 1967. Highway sculptures: the towers of satellite city. leonardo, Mexiko, v.3, n.80, p.319-322, 1970. . La verdad sobre las Torres de Satélite. Plural 2" época, v.X-I, n.109, p.41-44, 1980.

GRETENKORD, B. Traditioneller Wohnhausbau im mittleren Andengebiet. Berlin, 1984.

La influencia indigena en el arte de la región andina durante la época coloniallumboldt, Bonn, v.104, p.64-73, 1992a.

Kunstler der Kolonialzeit in Lateinamerika. Berlin, $1922 \mathrm{~b}$.

HARTEN, J. (Hg.) Barocke Malerei aus den Anden. 2 Bde. Düsseldorf, 1976.

HARTEN, J.; Eligio, A. (Hg.) Kuba O. K. Aktuelle Kunst aus Kuba. Düsseldorf, 1990.

HARTUNG, H. Ciudades mineras de México: Tasco, Guanajuato, ZacatecasBoletin del CIHE, Caracas, v.I1, p.123-126, 1969.

HAUFE, H. Funktion und Wandel christlicher Themen in der mexikanischen Marelei des 20. Jahrhunderts. Bcrlin, 1978.

Porto Arte, Porto Alegre, v. 5, n. 8, p. 65-80, jun. 1993 
. Orozco und Beckmann: dic last der Geschichte. Baque, Spreitz, p.97-105, 1981 a.

Das traditionsproblem der mexikanischen moderne bei José Clemente Orozco. Zeitschrift fïr Kunstgeschichte, München, v.1, p.38-52, $1981 \mathrm{~b}$.

- Mompox und die Architektur der Karibik: die Begegnung der Kulturen in Rio Magdalena: $K$. Kohut, Rasse, Klasse und Kultur in der Karibik, Frankfurt, p. 153-182, 1989a.

António Máro und die transformation der Mythen. In: BECKER, W. (IIg.), António Máro, Gemălde, Zeichnungen. Skulpturen, Aachen, 1989b. 363,1990 .

Stadterneuerung in Kolumbien, modelle und StrategienDie Alte Stadt, Stuttgart, v. 17, n.4, p.346-

Historische Kleinstädte in Mexiko: cine alternative. Humboldt, Bonn. v.105, 1992.

HАUPT, G. Zur Entstehung der mexikanischen Wandmalereibewegung. Roskok, 1979.

IIULEK-GNARIG, A. Malerei in Brasilien 1922 bis 195/. Nationale Selbstdefinition und Kunst. Berlin, 1988.

KETTENMANN, A. Frida Kahlo. Köln, 1922.

KOHI, K. H. (Hg.) Mythen der Neuen Welt. Zur Entdeckungsgeschichte I ateinamerikas. Berlin, 1982.

KÜGEI.GFN, H. von. Furopaischer Buchexport von Sevilla nach Neuspanien im Jahre 1586. Das Mexiko Projekt der DFG, Bd. 5, Wiesbaden, 1973.

Aspectos iconológicos en los murales de la Casa del Deán en Puebla. In:

Commenicaciones 16, Proyecto Pucbla - Tlaxcala. Puebla, 1979.

The way to Mexican Identity. In: INTFRNATIONAL. CONGRESS OF THE HISTORY OF ART

(25: 1986: Washington). Anais... Washington, p.709-720, 1989.

El índio: bárbaro ylo buen salvage? La imagen del indio en la Europa del siglo XVI y XVII. In:

La imagen del indio en la Europa moderna. Sevilla, 1990, p.457-487.

Texte zu erdteil - Allegorien. In: SIEBENMANN, G.; KONIG, H. J. (Hg.)Das Bild Lateinamerikas im deutschen Sprachraum. Ein arbeitsgespräch in der Herzog August Bibliothek Wolfenbüttel. Beihefte zur Ibereoromania, 8. Tübingen, 1992.

KUGELGEN, H. von; ROTHE, A. (Hg.) Erwin Walter Palm. Heimkehr ins Exil. Schritten zu Literatur und Kunst. Forum Ibero-Americanum, 6. Köln, 1992.

LÖSCHNFR, R. Bellermann und die venezolanische Landschaft. Caracas, 1977.

Deutsche Kunstler in Lateinamerika. Maler und Naturforscher des 19. Jahrhunderts illustrieren einen Kontinent. Berlin, 1978.

Johann Moritz Rugendas in Mexiko. Malerische Reise in den Jahren 1831-1834. Berlin, 1984.

Otto Grashoff. die Reisen des Malers in Argentinien. Uruguay. Chile und Brasilien 1852-1857. Berlin, 1987.

LUKS, I. Tipologia de la escultura decorativa hispánica en la arquitectura andina del siglo XVIII. Heidelberg, 1972.

Tipología de la escultura decorativa hispánica en la arquitectura andina del siglo XVIII. Boletín del CIHE, Caracas, v.17, 1973.

MUNZBFRG, O. Tamayo: eine mexikanische kontroverse. Ruckhaberle, p.134-208, 1990.

MUNZBERG, O.; NUNGESSER, M. Die mexikanischen Wandmaler Orozco, Rivera und Siqueiros in den USA. In: . America Traum und Depression 1920-1940. Berlin, 1980.

Porto Arte, Porto Alegre, v. 5, n. 8, p. 65-80, nov. 1993 
Geburt der mexikanischen Wandmalereibewegung. Vom Schöpfungsmythos zur revolutionären Dreieinigkeit. Berlin,1984.

Wandmalerei: eine Erscheinungsform von Urbanität und potentieller Stadtkultur. Zur theorie und Entwicklung der Wandmalerei im 20. Jahhundert. Die neue Gessllschaft, Frankfurter Hefte, 10. Bonn, 1985. $912 \mathrm{p}$.

(Hg.) Diego Rivera 1886-1957. Berlin, 1987.

NUNGESSER, M. Ein anderer Weg. Tamayos werk in der rezeption. Ruckhaberle, p.113-131, 1990.

PALM, E. W. Los monumentos arquitectónicos en la Española: con una introducción a América. 2 Bde. Barcelona: Neuauflage Santo Domingo, 1982.

Spanische und Hispano-Amerikanische Architektur. In: HUBALA. E. (Hg.) Die Kuns/ des 17. Jahrhunderts. Propyläen Kunstgeschichte, Bd.9, 1970. p.225-236. Arquitectura y arte colonial en Santo Domingo. Santo Domingo, 1974.

I. a fachada de la Casa de Los Muñecos en Puebla: un trabajo de Ilércules en el Nuevo Mundo. In: INSTITUTO DE INVESTIGACIONES ESTÉTICAS (18: 1978: Mexiko). Anales... Mexiko, 1978. p.35-46. La place excentrée. Plazas et Sociabilité en Europe el Amerique Latine, Paris, p.173-184, 1982.

Festschrift zum 70. Geburststag, hg. von H. von Kügclgen. JbLA, 20. Köln, 1983. Mit Vita und Bibliographic der Publikationen Palms.

Erinnerungen und Texte. IAA, Jg. 15, Bd. 4. Berlin, 1989.

PAZ, O. \%wiesprache: essays zu Kunst und literatur. Frankfurt, 1984.

PAZ, O.; LASSAIGNE, J. Rufino Tamayo. München, 1986.

PRIGNITZ, H. TGP; ein grafiken-kollektiv in Mexiko von 1937-1977. Berlin, 1981.

PRIGNITZ-PODA, II.; GRIMBERG, S.; KETTLNMANN, A. (1lg.) Frida Kahlo: das gesamtwerk. Frankfurt, 1988.

RODRIGUF/, А. Der Mensch in Flammen: Wandmalerei in Mexiko von den Anfängen bis zur Gegenwart. Dresden, 1967.

RUCKHABFRI.E, D. (Hg.). Rufino Tamayo. Berlin, 1990.

SECKER, H. Diego Rivera. Dresden, 1957.

TFJEIRA-DAVIS, E. Roots of modern latin american architecture: the hispano-caribbean region from the late 19 th century to the recent past. Heidelberg, 1987.

TIBOL, R. Die Kunst Mexikos III: mexikanische Kunst des 19. und des 20. Jahrhunderts. München, 1970.

WAND Bild Mexico. Berlin, 1982.

WEDEWER, R.; BANKMANN, U. Steine und Orte: altmexikanische stcinskulpturen und plastiken der gegenwart. Heidelberg, 1991.

WEISSGÄRBFR, H. Die skizzenbücher Ferdinand Bellermanns von seiner Reise durch Venezuela von 1842 1845. Forschungen und Berichte, Berlin, v.29-30, p.231-250, 1990.

WERRY, E. (Hg.). Mathias Goeritz: ein Deutscher Kunstler in Mexiko. Marburg. 1987. 1991. . Mathias Goeritz, Leben und Werk (19/5-1990): monographic mit Werkverzeichnis. Heidelberg.

WESTHEIM, P. Tamayo. Mexiko, 1957. 